\title{
O antiniilismo estético e a superação do niilismo*
}

\author{
Luis Enrique de Santiago Guervós**
}

\begin{abstract}
Resumo: Este artigo pretende mostrar que o niilismo no pensamento nietzschiano, além de ser um fenômeno histórico e um modo de ser do homem, é também fundamentalmente um fenômeno estético que assume a finitude da condição humana. Assim, Nietzsche, ao descrever o desenvolvimento do niilismo, quer narrar ao mesmo tempo sua própria vida. Ademais, o niilismo não pode ser superado de fora de seu próprio ponto de vista, mas deve ser superado desde dentro e somente por alguém que o vivenciou: isso só é possível mediante fazer de si mesmo uma obra de arte.
\end{abstract}

Palavras-chave: niilismo, criação, arte, vida.

* Tradução de Wilson A. Frezzatti Jr.

** Professor Doutor na Universidade de Málaga, Espanha: Correio eletrônico: lesantiago@uma.es. Heidegger, v. I, 2000, p. 46.

Cad. Nietzsche, Guarulhos/Porto Seguro, v.39, n.3, p. 11-29, setembro/dezembro, 2018. | 11 
Guervós, L. E. de S.

\section{O niilismo como "fenômeno estético"}

A análise que Nietzsche faz do niilismo, como é sabido, ocupase de determinar sua origem, sua sintomatologia e, sobretudo, as consequências que tem para o homem e seu mundo. Por isso, definese, em um primeiro momento, como fenômeno histórico, como um "processo fundamental de nossa história ocidental", ${ }_{1}^{1}$ ou seja, como a consequência lógica da tradição metafísica e da interpretação de mundo cristão-platônica, uma "consequência necessária do ideal atual" (Nachlass/FP 1887, 10 [42], KSA 12.476) ${ }^{2}$ que se fundamenta: na crença de verdades absolutas, na suposição de uma linguagem unívoca, na postulação de um sujeito objetivo, isto é, na história da cultura ocidental desde Platão até nossos dias, a qual é por sua vez - a história do niilismo. Além disso, o niilismo é um princípio ativo na história. Sempre esteve aí, ainda que não o tenhamos querido; está em todas as partes e não está em nenhuma. É um universo cujo centro está presente em tudo e cuja circunferência não aparece, como diria Pascal. Porém, desta vez se aproximou demais da porta. Ele bateu, e deixamos entrar o "mais inquietante de todos os hóspedes", por ser "a renúncia radical do valor, do sentido, da possibilidade de desejar" (Nachlass/FP 1885-1886, 2 [127], KSA 12.125). Nietzsche trata de interpretar esses acontecimentos, tudo o que foi produzido de maneira niilista, entretanto não o faz de uma distância objetiva, mas desde o mais íntimo de seu ser. O niilismo se revela, portanto, como a história de nossa época, mas essa história é, como diria Heidegger, "o modo mesmo em que estamos e que nos movemos, o modo mesmo que somos". ${ }^{3}$

1 Heidegger, v. I, 2000, p. 46.

2 As citações de Nietzsche foram traduzidas do texto original em espanhol. Para as obras publicadas, o autor utilizou os textos da edição de Andrés Sánchez Pascual, Alianza Editorial, Madrid. Por vezes, recorremos a KSA para aprimorar nossa tradução (Nota do tradutor).

3 Heidegger, v. I, 2000, p. 76.

12 | Cad. Nietzsche, Guarulhos/Porto Seguro, v.39, n.3, p. 11-29, setembro/dezembro, 2018. 
Assim, o niilismo, além de um fenômeno histórico, é, antes de tudo, um modo de ser do homem que está no reto caminho de sua afirmação, é a experiência fundamental do homem que quer “superar a si mesmo". Não é, portanto, uma corrente filosófica à qual se poderia aderir, mas é a condição de finitude própria do homem. De modo que, se o niilismo tem em primeiro lugar um efeito de dissolução, este se realiza não só no tempo, mas também no corpo. Por isso, Nietzsche quer ser aquele que, ao descrever o progresso do niilismo, narra ao mesmo tempo sua própria vida. ${ }^{4}$ Desse modo, o niilismo não pode ser superado de fora de seu próprio ponto de vista, mas pode e deve ser refutado e superado desde dentro, estrategicamente, e somente por alguém que o viveu e o sofreu. E esse alguém, em nosso caso, é o próprio Nietzsche. O niilismo, assim, se confunde também com a própria autobiografia de Nietzsche. Eu sou "o primeiro niilista perfeito da Europa, mas que já superou o niilismo que habitava em sua alma, vivendo-o até o fim, - deixando-o atrás de si, debaixo de si, fora de si" (Nachlass/ FP 1887-1888, 11 [411], KSA 13.189). Em outro texto, ele corrobora a mesma ideia quando afirma que suas obras falam apenas de suas superações: "nelas estou eu" (MA II/HH II, Prefácio 1, KSA 2.369). Nietzsche pensa, desse modo, que é necessário afirmar o niilismo como a essência do homem para ir além dele. E, assim, não estaríamos de novo imersos num jogo entre a afirmação do abismo e o poder transcendê-lo?, não seria necessário entrar novamente na dialética que salvou os gregos quando eles estavam entre a terrível profundidade e a bela superfície ou aparência?

Portanto, o niilismo, além de ser um fenômeno histórico e um modo de ser do homem, é também considerado por Nietzsche fundamentalmente um fenômeno estético. Ou seja, trata-se de mostrar como a superação do niilismo só é possível mediante um ato produtivo do homem, ou ainda através de uma ação artística.

4 Cf. Andreas-Salomé, 2005, p. 53 e Andler, 1952. 
Guervós, L. E. de S.

Se o mundo em si já não tem sentido, deve-se dar-lhe um novo por meio de um ato criador. Por isso, não é estranho que Nietzsche, ao contemplar o problema do niilismo europeu, o pensasse novamente da perspectiva unitária da arte, pois tanto o niilismo como a arte se explicam melhor em sua filosofia quando se relacionam no âmbito de uma tensão essencial.

Esse vai ser o contexto de nossa apresentação, já que consideramos que a relação entre niilismo e arte é um problema central na filosofia de Nietzsche, no qual se decide realmente se o homem tem ainda um futuro. É necessário elucidar, portanto, como a estética joga um papel essencial nesse contexto, e como a luta ativa contra o niilismo passa necessariamente pelo caminho da arte, na medida em que, para Nietzsche, criar é o valor supremo, pois aquele que cria pode desenvolver livremente todas suas potencialidades. Mas por que a arte? Em primeiro lugar, porque a estética de Nietzsche se estabelece desde a perspectiva do artista; porque o artista representa o modelo de homem que supera a si mesmo e o protótipo que se opõe ao moralista e ao filósofo; porque o problema da arte se desdobra sempre no horizonte problemático da relação arte-vida; finalmente, porque a arte é a única força superior oposta a toda vontade de negar a vida, é a única força que não somente percebe o carácter terrível e enigmático da existência, mas que o vive e deseja vivê-lo. Essa forma de colocar o problema é marcada pelo próprio Nietzsche em uma expressão: "antiniilismo estético", isto é, outra forma de falar da necessidade de superar a metafísica pelo caminho da estética. Quase de um modo programático, ele resume em um texto tardio seu ponto de vista sobre o problema:

"A arte e nada mais que a arte! É a única que torna a vida possível, é a grande tentação que convida a viver, o grande estimulante para a vida. A arte como a única força antagonista superior diante de toda vontade de negar a vida, a arte diante de toda negação da vida, a arte como anticristã, antibudista, antiniilista por excelência" (Nachlass/FP 1888, 17 [3], KSA 13.522).

14 | Cad. Nietzsche, Guarulhos/Porto Seguro, v.39, n.3, p. 11-29, setembro/dezembro, 2018. 
Pode-se dizer, em suma, que a estética de Nietzsche significa, de certo modo, sua posição e resposta frente ao niilismo, pois a arte tem uma função antiniilista, já que o sim puro à vida aparece particularmente privilegiado na atividade propriamente artística ou em uma relação estética com as condições de vida concretas. E essa função antiniilista da arte se apresenta como a única solução possível frente ao niilismo dos filósofos. Isso porque tanto o filósofo como o moralista são um tipo essencialmente reativo, enquanto que o artista é sempre afirmativo.

"Os artistas", diz Nietzsche, "são produtivos porque eles modificam e transformam realmente: não são como os que conhecem, que deixam todas as coisas como estavam" (Nachlass/FP 1887, 9 [60], KSA 12.364). Zaratustra ama "quem quer criar para além de si” (ZA/ZA II, Do imaculado conhecimento, KSA 4.156). O artista sempre se eleva além do pessimismo e do niilismo, inclusive quando o abraça, pois a arte é a práxis transfiguradora do amor fati, afirmação efetiva, um Sim puro. Gottfried Benn interpretava essa perspectiva de Nietzsche a partir da experiência da arte como a tentativa de "pôr frente ao niilismo generalizado dos valores uma nova transcendência", "a transcendência do prazer criador", 5 ou seja, um transbordamento para além dos limites da consciência humana que não é outra coisa que "a exploração artística do niilismo". Durante esse transcender, no momento do processo criador do transbordamento, abre-se o carácter fundamental do ente. "Em certos estados de ânimo", diz Nietzsche, "pomos, transfiguramos e comunicamos plenitude às coisas, e as elaboramos com o pensamento enquanto refletem nossa própria plenitude e alegria de viver" (Nachlass/FP 1887, 9 [102], KSA 12.393).

Podemos dizer, portanto, que a relação do niilismo com a arte é delimitada por Nietzsche dentro do chamado niilismo ativo, pois essa forma de niilismo se identifica com a força e a potência, ou seja, adquire uma dimensão de força tão grande que destrói os valores absolutos:

5 Benn, 1989, p. 510. Cf. também Daboul, 1995, p. 19 e Hillebrand, 1966 e 1991. 
Guervós, L. E. de S.

"O grau de força de vontade é medido segundo o grau que se possa dispensar as coisas de sentido, segundo se possa suportar a vida em um mundo desprovido de sentido" (Nachlass/FP 1887, 9 [60], KSA 12.364). Ademais, essa medida de forças é o que, segundo Nietzsche, "nos permite assumir por nós mesmos a aparência, a necessidade de mentira sem perecer. $\mathrm{O}$ niilismo, assim, como negação de um mundo verdadeiro, de um ser, poderia ser uma divina maneira de pensar" (Nachlass/FP 1887, 9 [41], KSA 12.354). Logo, para Nietzsche, toda superação do niilismo depende em realidade desse "novo princípio" que é o grau de força, vontade de potência, que nos permite tomar consciência de que a aparência e a mentira constituem os elementos essenciais para poder suportar a existência. São, portanto, necessárias a força e a potência próprias do artista para poder suportar e transcender que não há verdade, que não há fatos, que não há nada “em si”, enfim, que não há Deus. Por isso mesmo, esse niilismo é indispensável, é condição necessária para ir além dele. É o martelo que destrói as palavras, os conceitos absolutos, para liberar essa nova energia que transformará a realidade em outra coisa e elevará a vida a um novo nível. Os fracos preferem que tudo termine, porque são incapazes de oferecer novas alternativas, entretanto:

uma forma de pensar e uma doutrina pessimista, um niilismo extático, podem, em certas circunstâncias, ser indispensáveis para o filósofo como poderoso meio de pressão e martelo para destruir as raças degeneradas e moribundas, para tirá-las do caminho, para elevar a vida a um novo nível ou para inspirar aos degenerados e decadentes o desejo de acabar (Nachlass/ FP 1885, 35[82], KSA 11.547).

\section{A arte como "contramovimento" do niilismo}

Partindo-se desses pressupostos, pode-se dizer que Nietzsche utiliza uma vez mais a via estética, e, sobretudo, sua ideia da "vontade de potência como arte", como uma estratégia que ele

16 | Cad. Nietzsche, Guarulhos/Porto Seguro, v.39, n.3, p. 11-29, setembro/dezembro, 2018. 
O antiniilismo estético e a superação do niilismo

define, nesse caso, como "contramovimento" contramovimento futuro que substituirá esse niilismo, mesmo se o pressuponha como necessário. Em outras palavras, a autêntica e verdadeira superação do niilismo deve ser produzida através da arte, entendida como esse impulso transformador necessário para que as coisas sejam de outra maneira. Contudo, esse "contramovimento" se expressa "dialeticamente" de formas diversas: como negatividade produtiva e como autocriação do homem, e como o caminho que converte o homem em obra de arte.

\section{Negatividade produtiva do niilismo}

Nietzsche, que fala como "o primeiro niilista perfeito da Europa" (Nachlass/FP 1887-1888, 11 [411], KSA 13.190, e 1887, 10 [43], KSA 12.476), pensa que esse perfeito niilista ainda não é criativo, não é ainda filósofo, não é capaz de dar e pôr sentido à realidade. Por isso, explica esse contramovimento, em primeiro lugar, como negatividade, pois o processo de criação de novos valores, ou o processo que nos leva à superação do niilismo, contém necessariamente um momento de negação, ainda que não se possa equiparar negação com niilismo. O niilismo se volta contra si mesmo para superar-se. Nega-se para engendrar e criar um resultado novo. Por isso, Heidegger diz que a superação do niilismo se realiza mediante um "processo de radicalização". ${ }^{7}$ Assim, a concepção de Nietzsche do niilismo gira em torno de uma estrutura dialética. O chamado niilismo passivo, ou reativo, característico da modernidade, é pura negatividade, "um estado de transição" (Nachlass/FP 1887-1888, 11 [100], KSA 13.49) que encontra também no budismo sua primeira expressão histórica (cf. Nachlass/FP 1887, 9 [35], KSA 12.351).

6 Sobre a "A arte como contramovimento", cf. Nachlass/FP 1869-1870, 3 [33], KSA 7.69, e 1888, 14 [14], [35], [47], [117], [119] e [170], KSA 13.224, 235, 241, 293, 296 e 356. Cf. também MüllerLauter, 2000, p. 177ss.

7 Heidegger, v. II, 2000, p. 280. Cf. também Granier, 1966, p. 287.

Cad. Nietzsche, Guarulhos/Porto Seguro, v.39, n.3, p. 11-29, setembro/dezembro, 2018. $\mid 17$ 
Guervós, L. E. de S.

Nesse estado, "as forças produtivas ainda não são suficientemente fortes" (Nachlass/FP 1887, 9 [35], KSA 12.351). Essa forma de niilismo, afirma Nietzsche, deve ser negada pelo niilismo ativo, que implica uma negatividade determinada, que consiste em pôr, no sentido de interpretar, novos valores e um novo sentido nas coisas, mediante um ato criador que não somente nega os valores existentes ("vontade de nada"), mas cria novos valores em virtude da "força e potência" do homem que chegou a ser artista. O próprio Nietzsche considera uma sorte ter voltado "a encontrar, depois de milênios de confusão e extravio, o caminho que conduz a um Sim e a um Não. "Ensino o Não frente a tudo que debilita, contra tudo aquilo que esgota. Ensino o Sim a tudo que fortalece, àquilo que acumula força" (Nachlass/FP 1888, 15 [13], KSA 13.412). No entanto, não se supera o niilismo por ser um niilista ativo, como tampouco se passa meramente do niilismo passivo ao ativo, transcende-se o niilismo pela criatividade, considerada como o valor supremo. Nietzsche observa ironicamente: "quem nada cria, cria um nada" (Nachlass/FP 18841885, 29 [59] e 31[43], KSA 11.350 e 379, e 1888, 20 [155], KSA 13.574), pois o niilista, o homem do ressentimento $n$ ão cria um dizer $n$ ão, já que a perda do sentido, unida à experiência da falta de força, é o que o impede de seguir acreditando no fundamento das coisas e de autocriar-se. É necessário sobreviver à dor dessa negação, pois "o niilismo é o reconhecimento de um contínuo desperdício de força, a agonia do em vão" (Nachlass/FP 1887-1888, 11 [99], KSA 13.46). Portanto, esse processo negativo necessita da força e da potência para negar e transcender-se, pois a exigência da negatividade é a fonte da exuberância, do excesso necessário para a criatividade. "Vós conheceis unicamente centelhas do espírito", falava Zaratustra, mas não vedes a bigorna que ele é, nem tampouco a crueldade de seu martelo!" (ZA/ZA II, Dos sábios famosos, KSA 4.132).

Em Genealogia da moral, na terceira dissertação, no contexto dos "ideais ascéticos" como resposta da vontade humana ao horror

$18 \mid$ Cad. Nietzsche, Guarulhos/Porto Seguro, v.39, n.3, p. 11-29, setembro/dezembro, 2018. 
O antiniilismo estético e a superação do niilismo

vacui, a famosa história do rei Vishvamitra do Ramayana, recordanos a mesma situação acima: esse filósofo asceta,

à base de automartirizar-se durante milênios, adquiriu tal sentimento de potência e tal confiança em si, que se dispôs a construir um novo céu: o inquietante símbolo da mais antiga e moderna história dos filósofos na terra, - todo aquele que alguma vez construiu 'um novo céu' encontrou antes a potência para isso em seu próprio inferno..."(GM/GM III, 10, KSA 5.359).

De novo aparece aqui essa tensão entre autonegação e superação, unida à autocriação. A mesma ideia se expressa quando nos apresenta a imagem daquela larva que encerrava dentro de si o espírito: pode sair à luz, a um mundo quente, mais luminoso, com mais sentido? Para isso, é necessário, dirá Nietzsche, que exista "suficiente orgulho, ousadia, valentia, segurança em si mesmo, vontade de espírito, vontade de responsabilidade, liberdade da vontade" (GM/GM III, 10, KSA 5.359) para que seja possível a superação do niilismo.

Contudo, para compreender melhor o sentido e as condições da criatividade, como "contramovimento" do niilismo, nos remetemos ao paradigma exemplar das transmutações do espírito tal como o descreve Nietzsche em seu Zaratustra (cf. ZA/ZA I, Das três transmutações, KSA 4.29).8 Aí se investiga o "processo" que conduz à transmutação em verdadeiros criadores e os critérios que distinguem uma ação criativa de qualquer outra ação. A ação criativa sempre tem lugar em um contexto determinado, e se requer do artista criativo, em primeiro lugar, que assuma livremente esse contexto como algo naturalmente seu. Nesse sentido, o homem criativo deve realizar a transmutação do camelo, porque através de sua realização toma consciência das limitações e condições de sua criatividade. O camelo nos descobre o ponto de partida: o reconhecimento da tradição, de maneira que realizar essa transmutação é chegar a ser histórico. ${ }^{9}$ O segundo

8 Cf. também Gillespie; Strong, 1988.

9 Cf. Gillespie; Strong, 1988, p. 145.

Cad. Nietzsche, Guarulhos/Porto Seguro, v.39, n.3, p. 11-29, setembro/dezembro, 2018. 
Guervós, L. E. de S.

momento do processo é o "não" do leão, que quer conquistar sua liberdade criadora e criar as condições sob as quais a livre criação possa realizar-se: "criar liberdade para um novo criar" (ZA/ZA I, Das três transmutações, KSA 4.30). Por isso, mediante a luta do leão contra os valores supremos e seu fundamento transcendente, o homem cria sua liberdade, libera a liberdade que se escondia nele. Mas essa liberdade "negativa" que diz "não" aos valores supremos, a Deus, às ilusões da moral, à "coisa-em-si", etc., é somente a "liberdade de", mas não a "liberdade para". 10 Dessa forma, Nietzsche pensa que essa negação da transcendência de tais valores, ou a superação da autoalienação humana da existência, não seja ainda uma nova produtividade criadora, um querer criador. $\mathrm{O}$ niilista ativo se parece, assim, ao espírito do leão de Zaratustra, como este é livre, mas sem pátria, busca destruir a ordem existente.

Mas ao "eu quero" do leão ainda falta criar novos valores. E isso é o que faz a criança.

Inocência é a criança, e esquecimento, um novo começo, um jogo, uma roda que se move por si mesma, um primeiro movimento, um santo dizer sim. Sim, meus irmãos, para o jogo do criar é necessário um santo dizer sim (ZA/ZA I, Das três transmutações, KSA 4.31).

Em um texto não publicado, expressa a mesma ideia de outra maneira: "Terceira fase. A grande decisão: capacidade para uma atitude positiva, para dizer sim. Nem deus nem homem para além de mim! $O$ instinto criador, que sabe onde põe a mão. A grande responsabilidade e a inocência" (Nachlass/FP 1884, 26 [47], KSA 11.160). Aqui temos os elementos que melhor definem esteticamente o sentido da criatividade que Nietzsche sustenta para transcender o niilismo: esquecimento, inocência, novo começo, dizer Sim e, sobretudo, o criar como o prazer do "jogo" da criança. Com isso,

10 "Livre de quê? Que importa isso a Zaratustra! Teus olhos me devem anunciar com claridade: livre para quê?"” (ZA/ZA I, Do caminho do criador, KSA 4.81). Cf. também Fink, 1969, p. 84.

$20 \mid$ Cad. Nietzsche, Guarulhos/Porto Seguro, v.39, n.3, p. 11-29, setembro/dezembro, 2018. 
parece dizer-nos que o homem pode afirmar verdadeiramente sua autonomia, quando se apropria de novo do mundo do qual se separou; somente pode retornar a si mesmo se alcançar o estado de inocência da criança joga, porque a criança que joga é livre, porque não quer nada e realmente cria; por isso, seu jogo é a expressão da mais alta afirmação da vida. Em todo momento está ligado ao presente, não se volta para o passado, nem mira o futuro.

Assim, Zaratustra vai mostrando ao longo de seus discursos como se exemplifica em sua pessoa o "sagrado sim" da criança, associando à capacidade de criar ojogo e a inocência infantil. O que é corroborado quando é feita a pergunta: “Onde há inocência? Ali onde há vontade de engendrar. E aquele que quer criar para além de si mesmo tem, para mim, a vontade mais pura" (ZA/ZA II, Do imaculado conhecimento, KSA 4.157). É que a criança não conhece ainda a sedução das máscaras e joga ainda despreocupadamente, porque está desprovida de qualquer sentido de responsabilidade e de culpa, as quais impedem o homem de agir e promovem a má consciência do recordar. A criança é "inocência e esquecimento", e, desse modo, é aquele que pode expressar o "sim à vida" [Ja-sagen] em seu ciclo eterno de nascimento e morte, já que esse é "o jogo da criação", ou seja, um jogo "cruel" que possui também a marca da destruição e da negação. Como disse Deleuze: "a destruição enquanto destruição ativa do homem que quer perecer e ser superado é $o$ anúncio do criador". 11

Portanto, com a ideia da criança que cria jogando, Nietzsche procura ir além do niilismo, pois a superação do niilismo não consiste em "encontrar" novas metas ou crenças, porém em criá-las, e a condição de possibilidade de tal criação é uma força suficiente, a vontade de potência. $\mathrm{O}$ mundo, concebido como um incessante "jogo de forças" que se autocria indefinidamente, produz as mesmas combinações que num enorme jogo de números, "o grande jogo da

11 Deleuze, 1986, pp. 248-249. 
Guervós, L. E. de S.

existência". Além disso, essa figura da criança vai se configurando no Nietzsche maduro como um novo Dioniso, que não estará simplesmente reduzido ao aniquilador do niilismo ativo, mas que é também o mediador para um novo mundo de valores, Dioniso-philosophos; agora não simboliza exclusivamente o deus do frenesi e da paixão, converte-se num símbolo para a paixão sublimada e para afirmação da vida. Seu oposto já não é o apolíneo, mas o cristianismo: Dioniso versus Apolo se transforma em "Dioniso contra o crucificado" (EH/ EH, Por que sou um destino 9, KSA 6.374). ${ }^{12}$ "O problema" - diz Nietzsche - "é o significado do sofrimento: um sentido cristão ou um sentido trágico" e "Dioniso despedaçado é uma promessa de vida: esta renascerá eternamente e retornará da destruição" (Nachlass/ FP 1884, 14 [89], KSA 13.265-6).

$\mathrm{O}$ "sim à vida", como expressão suprema da existência, se identifica com o ato criador. Por isso, quando Nietzsche relaciona a arte com a vida, não hesita em afirmar que a arte é "a verdadeira tarefa da vida, a arte como a atividade metafísica da vida, a arte como o grande estimulante da vida" (GD/CI, Incursões de um extemporâneo 24, KSA 6.127, e Nachlass/FP 1887, 9 [119], KSA 12.404). Com essas proposições, põe em destaque que a arte é como uma função da vida e que o processo transfigurativo não é outra coisa que a passagem de uma "vontade de verdade" a uma "vontade de criação", o que significa, segundo Sojcher, "haver obtido da autossupressão da primeira (a lógica do niilismo) os recursos para a autoafirmação da segunda, haver mudado o signo da vontade". ${ }^{13}$ Superar o niilismo passivo, o pessimismo da debilidade, significa transformar o verdadeiro sentido da vontade que se converte em vontade de criar em "vontade de potência" como arte. E isso é assim, porque, para Nietzsche, a arte quer a vida, por isso mesmo a arte

$12 \mathrm{EH} / \mathrm{EH}$, Por que sou um destino 9 finaliza a obra. O parágrafo 9 completo é: "Compreenderam-me?

- Dioniso contra o Crucificado...”. Cf. também Nachlass/FP 1888, 14 [89] e [137], KSA 13.265 e 321.

13 Sojcher, 1972, p. 94.

22 | Cad. Nietzsche, Guarulhos/Porto Seguro, v.39, n.3, p. 11-29, setembro/dezembro, 2018. 
é mais poderosa que o conhecimento, pois a vida só é possível se ilusões artísticas forem potencializadas.

A grande antítese de Nietzsche é, portanto, a antítese entre o nada e o criar, de modo que o desenvolvimento da atividade criadora tenha sua razão de ser no niilismo, ou seja, toda atividade criadora se fundamentaria no niilismo, tal como, mais tarde, Heidegger diria que o fundamento do ser é o nada. Nietzsche expressa isso de outra forma quando afirma que "o niilismo pode ser um sintoma da força crescente, ou da debilidade crescente" (Nachlass/FP 1887, 90 [60], KSA 12.367). Somente quando se chega ao limite, quando se tensiona até o seu extremo o arco sob a força dos impulsos profundos do homem criador, é que os valores podem sofrer sua própria transvaloração. Isto é, unicamente a grande afirmação da existência, o dizer Sim à vida, pode resultar em algo efetivo, quando a vontade de nada, a Grande negação, destruiu todas suas formas.

\section{O homem como "obra de arte": o caminho até o fim do niilismo}

Para transformar o niilismo, pelo caminho da arte, para superálo em sua essência, o próprio criador, que toma consciência dessa atividade, deve também chegar a ser ele mesmo uma obra de arte. Esse outro mundo de sentido, além do niilismo, é, portanto, um resultado cuja condição de possibilidade é o homem criador, "aquele que cria a meta do homem e que dá seu sentido à terra e a seu futuro" (ZA/ZA III, Das velhas e novas tábuas 2, KSA 4.247), aquele que "utiliza a força não sobre a obra, mas sobre si mesmo enquanto obra" (M/A, 548, KSA 3.319). E, nesse processo transformador que supõe a arte frente ao niilismo, o artista, em seu sentido originário, já não é tanto aquele que produz obras de arte, mas aquele que produz sua própria vida, aquele que converte seu próprio eu num "fenômeno estético". Nietzsche se expressa igualmente na primeira seção de $O$ nascimento da tragédia ao descrever o processo criador: "O homem 
Guervós, L. E. de S.

já não é mais artista, converteu-se em uma obra de arte" (GT/NT, 1, KSA 1.29). ${ }^{14}$ Por acaso, - perguntava-se Paul Valery - não se deve conceber a produção de uma obra de arte como obra de arte?

Nietzsche parece indicar-nos com isso que, no processo criativo, se dá uma dupla projeção. Em um sentido, para ele o essencial, o homem como artista não visa a obra de arte exterior, mas o verdadeiramente importante é que, à medida que cria, se transforma, convertendo-se em "uma obra de arte". Chegar a ser uma "obra de arte" é "chegar a ser o que se é", significa "fazer emergir além de si mesmo o homem", esse é o novo conceito de arte: "contra a arte da obra de arte" (Nachlass/FP 1881, 11 [170], KSA 9.506). Nesse sentido, a obra de arte que o homem chega a ser seria algo como um espelho no qual se reflete a sua própria perfeição, enquanto a obra de arte externa não seria mais que uma simples projeção do que é. Além disso, essa capacidade involuntária de projetar para fora sua vitalidade ingênua o converte em artista, pois ao mesmo tempo transforma o mundo ao redor, e "este ter-que-transformar as coisas em algo perfeito é - arte. [...]; na arte o homem goza de si mesmo como perfeição" (GD/CI, Incursões de um extemporâneo 9, KSA 6.116).

$\mathrm{O}$ sentido experimental dessas ideias tem como modelo e referência a própria obra de Nietzsche, pois o processo de superação do niilismo não só é um processo filosófico, mas também vital, que tem sua exemplificação na própria vida de Nietzsche. A própria vida do filósofo, e não tanto suas obras, é "sua obra de arte", porque toda obra de arte não é mais que o reflexo dessa outra obra de arte, já que a filosofia será autobiografia ou não será filosofia (Nachlass/FP 1873, 29 [205], KSA 7.712). O produto do filósofo é antes de tudo sua vida, antes que suas obras. Para Nietzsche, portanto, tudo volta a ter sentido e valor à medida que o homem supera a si mesmo e, enquanto "obra de arte", irradia com sua perfeição todas as coisas,

14 Cf. também DW/VD, KSA 1.553ss, GG/NP, KSA 1.581ss, e Nachlass/FP 1869-1870, 3 [28], KSA 7.68, e 1870-1871, 7[40], KSA 7.148.

24 Cad. Nietzsche, Guarulhos/Porto Seguro, v.39, n.3, p. 11-29, setembro/dezembro, 2018. 
tornando o mundo habitável. As coisas serão belas porque o homem é belo; o mundo voltará a ter sentido porque no homem há harmonia. Esse é o caminho para superar o niilismo e para o novo "evangelho da harmonia", no qual se proclama como se pode converter a vida em algo belo, como devolver o sentido às coisas, como converter o caos e o nada em um mundo ordenado. A ausência de um deus providencial conduz a uma alegria suprema nas possibilidades artísticas do homem, porque a arte nos capacita a substituir essa desordem pela bela aparência, pois a beleza não está no que se representa (conteúdo), mas no modo em que se representa, ou seja, na "forma", já que "desfrutar da beleza é deleitar-se nas formas belas" (GT/NT, 16, KSA 1.104). Aqui está a chave da redução da arte à "bela aparência". Se a beleza se separa de seu conteúdo, então é verdadeiramente possível que o belo possa coexistir com esse fundo horrível e repulsivo da existência. A beleza redime, triunfa sobre o sofrimento e a dor, vence a sabedoria de Sileno, significa, como afirma Kaufmann, o triunfo de Apolo sobre Dioniso. ${ }^{15}$ E se não há uma ordem intrínseca nas coisas, e se o mundo em sua essência é um caos, nada mais grandioso que inventar histórias belas.

Portanto, a transformação do mundo e a transvaloração dos valores que leva à superação do niilismo pressupõem a transformação de si mesmo mediante atos criadores. Por isso, o processo criativo e experimental visto desde a perspectiva do artista tem também um valor fundamentalmente existencial. Enquanto um modo de experiência que implica diretamente a nossa própria noção de existência, é uma experiência essencial, porque configura nosso modo de ser no mundo. A estética pode ser entendida, portanto, como experiência do mundo, na qual o primordial é a afirmação como ato criador. Onde nada vale como resultado do niilismo, tudo deve "ser criado" de novo: o sentido da vida humana e o sentido das coisas, o primeiro como condição de possibilidade do segundo, porque, para poder dar,

15 Cf. Kaufmaann, 1974, p. 107.

Cad. Nietzsche, Guarulhos/Porto Seguro, v.39, n.3, p. 11-29, setembro/dezembro, 2018. 
Guervós, L. E. de S.

primeiro deve-se tomar consciência de si, de sua própria plenitude. $\mathrm{O}$ homem e a realidade em que vive são produzidos num processo criador; e, por isso mesmo, chegam a ser "obras de arte".

Logo, pode-se afirmar e dizer que a arte é uma consequência e uma expressão do "agradecimento de uma felicidade ditosa" (MA I/HH I, 117, KS 2.119), da glorificação da existência que se projeta em possibilidades inalcançáveis a partir da afirmação do mundo e da vida, que é possível em virtude de uma energia incontrolável e produtiva que possui em sentido amplo $o$ artista, mas que não possui o artista enquanto sujeito empírico. Por isso, afirma Nietzsche, que a consideração artística do mundo é um "pôr-se ante a vida" (Nachlass/ FP 1886-1887, 7 [3], KSA 12.256), ou melhor dizendo, um expor-se $a$ essa força originária e elementar.

Esse ideal de autocriação, cujo resultado é o homem chegar a ser "obra de arte", evidencia-se de uma maneira exemplar no gênio e nos seres superiores. O gênio chega a ser o artista de sua própria vida, criando suas próprias leis e criando a si mesmo. ${ }^{16}$ Nesse sentido, a primeira transformação que a arte produz refere-se ao artista, já que as produções estéticas são meras expressões externas. De fato, o artista sempre produz a si mesmo, em primeiro lugar, como obra de arte, e depois, em um segundo plano, aparece como um objeto de atração para os demais, pois, no transcurso de sua autossuperação, para chegar a ser o que se é, produz uma beleza que atrai os demais; por meio da autocriação, as figuras exemplares encarnam "o grande estímulo para viver", convidando de modo exemplar os outros para que se unam a ele, a fim de que possam elevar-se culturalmente.

Essa capacidade de autocriação, como atestado da superação do niilismo, é o elemento comum a todos os seres superiores. Eles são os redentores do passado e do futuro. Somente na medida em que são artistas, produtores de uma beleza que os excede, esses humanos exemplares cumprem com seu papel social como legisladores. A função

16 Sobre a política e a autocriação, cf. Thiele, 1990, p. 131ss.

$26 \mid$ Cad. Nietzsche, Guarulhos/Porto Seguro, v.39, n.3, p. 11-29, setembro/dezembro, 2018. 
política desses seres está resumida nestes termos: enquanto cuidam de sua autoperfeição, elevando suas próprias vidas, indiretamente elevam a vida de todos os outros que participam de um mesmo projeto cultural. O decisivo - afirma Nietzsche - é, portanto, "a força que um gênio aplica não à obra, mas a si mesmo como obra" (M/A, 548, KSA 3.319), ${ }^{17}$ porque o verdadeiramente importante aqui não é o fruto da árvore, mas a semente, a energia criadora.

A arte nos mostra, assim, que podemos desde nós mesmos criar a ordem, o sentido, a lógica, e que não temos de submetermonos a uma alternativa que possui somente estas duas opções, ou a fé em um Deus ou o caos e o niilismo. A arte nos ensina e nos proporciona a possibilidade de tomar consciência do que somos, ao mesmo tempo em que nos permite potencializar ao máximo a vida. Desse modo, mostra-se a função vital da arte frente ao niilismo e a transformação do próprio homem num "fenômeno estético", pois o homem criador é ele mesmo uma obra de arte. Nesse sentido, como indica Gerhardt, "a justificação estética é uma expressão da autossuficiência geral do mundo", ${ }^{18}$ ou seja, na medida em que não necessita de nenhuma relação significativa para além dele, ele é em si próprio tão significativo como pode ser uma obra de arte.

17 Em VM/OS, 406, KSA 2.533, Nietzsche afirma: "Todo desfrutador crê que o que importa na árvore é o fruto, quando o importante é a semente. - Nisso está a diferença entre todos os criadores e desfrutadores". Heidegger também se deu conta de que na estética de Nietzsche se falava pouco da obra de arte (cf. Heidegger, v. I, 2000, p. 138).

18 Gerhaardt,1984, p. 90. 
Guervós, L. E. de S.

\begin{abstract}
This article aims to show that nihilism in Nietzschean thought, besides being a historical phenomenon and a way of being of man, is also fundamentally an aesthetic phenomenon that presupposes the finitude of the human condition. Thus Nietzsche, when describing the development of nihilism, wants to narrate his own life at the same time. Moreover, nihilism cannot be overcome from outside its own point of view, but it must be overcome from within and only by someone who has experienced it: this can only be achieved through the self-creation as a work of art.
\end{abstract}

Keywords: nihilism, creation, art, life.

\title{
Referências bibliográficas
}

ANDLER, Charles. Nietzsche: sa vie et sa pensée. París: Gallimard, 1952.

ANDREAS-SALOMÉ, Lou. F. Nietzsche en sus obras. Tr. de L. F. Moreno Claros. Barcelona: Minúscula, 2005.

BENN, Gottfried. Essays und Reden. Ed. de Bruno Hillebrand. Frankfurt: Fischer, 1989.

DABOUL, Alexander D. Die artistische Ausnutzung des Nihillismus. Zum Kunstdenken von Benn und Nietzsche. Frankfurt: Haag-Herschen, 1995.

DELEUZE, Gilles. Nietzsche y la filosofía. Barcelona: Anagrama, 1986.

FINK, Eugen. La filosofía de Nietzsche. Madrid: Alianza, 1969.

GERHARDT, V. Artisten-Metaphysik. In: DJURIRIC, M.; SIMON, J. (eds.). Zur Aktualität Nietzsches I. Würzburg: Königshausen und Neumann, 1984.

GILLESPIE, Michael A.; STRONG, Tracy B. (eds). Nietzsche's new seas. Explorations in philosophy, aesthetics, and politics. Chicago: University of Chicago Press, 1988.

GRANIER, Jean. Le problème de la Vérité dans la philosophie de Nietzsche. Paris: Seuil, 1966.

HEIDEGGER, Martin. Nietzsche. Tr. de J. L. Vermal. Barcelona: Destino, 2000.

$28 \mid$ Cad. Nietzsche, Guarulhos/Porto Seguro, v.39, n.3, p. 11-29, setembro/dezembro, 2018. 
O antiniilismo estético e a superação do niilismo

HILLEBRAND, Bruno. Artistik und Auftrag. Zur Kunstheorie von Benn und Nietzsche. München: Nymphenburger Verlagshandlung, 1966.

HILLEBRAND, Bruno. Ästhetik des Nihilismus. Von der Romantik zum Modernismus. Stuttgart: Metzler, 1991.

KAUfMANN, Walter. Nietzsche. Philosopher, Psychologist, Antichrist. Princeton: Princeton University Press, 1974.

MÜLLER-LAUTER, Wolfgang. Heidegger und Nietzsche. Nietzsche -Interpretationen III. Berlín: Walter de Gruyter, 2000.

NIETZSCHE, F. Sämtliche Werke. Kritische Studienausgabe (KSA: 15 vols.). Hrsg. von G. Colli und M. Montinari. Berlin/New York: de Gruyter, 1988.

SOJCHER, Jacques. La question et le sens. Esthétique de Nietzsche. Paris: Aubier Montaigne, 1972.

THIELE, Leslie Paul. F. Nietzsche and the Politics of Soul. Princeton: Princeton University Press, 1990.

Artigo recebido para publicação em 14/06/2017 Artigo aceito para publicação em 09/11/2017 